\title{
Perinatal outcomes and intrahepatic cholestasis of pregnancy: a prospective study
}

\author{
Sangeeta Parihar ${ }^{1}$, Swatantar Singh ${ }^{2 *}$
}

\begin{abstract}
${ }^{1}$ Department of Gynecology, ${ }^{2}$ Department of Pediatrics, Government District Hospital, Rajouri, Jammu and Kashmir,
\end{abstract} India

Received: 11 January 2019

Accepted: 25 January 2019

\section{*Correspondence:}

Dr. Swatantar Singh,

E-mail: singhswatantar@gmail.com

Copyright: () the author(s), publisher and licensee Medip Academy. This is an open-access article distributed under the terms of the Creative Commons Attribution Non-Commercial License, which permits unrestricted non-commercial use, distribution, and reproduction in any medium, provided the original work is properly cited.

\begin{abstract}
Background: Women with intrahepatic cholestasis of pregnancy (ICP) have an increased risk for postpartum haemorrhage, dyslipidaemia, preterm labour and operative interference. Fetus in ICP has been associated with an increased incidence of preterm labour, preterm prelabour rupture of membrane, fetal distress, abnormal CTG, meconium staining, spontaneous intrauterine death. The present study was done to evaluate the perinatal outcomes maternal outcomes and fetal outcomes of ICP.

Methods: This was a prospective observational study carried out in a tertiary care teaching hospital. Total 1100 pregnant women were screened during the study period. Patients with ICP were identified in maternity care units after eliciting history about itching. Pregnancies with pregnancy induced hypertension and other liver diseases in pregnancy were excluded.

Results: 62 pregnant women with prevalence rate of $5.64 \%$ have been found to be suffering from ICP. The most frequently affected $(22,35.48 \%)$ age-group with ICP were belong to age > 35 years. A majority of pregnant women with intrahepatic cholestasis of pregnancy was of multipara. ICP was highly significantly associated with small for gestational age (SGA, p-value: 0.0003); abnormal cardiotocography (CTG, p-value: 0.0002); and meconium stained liquor (p-value: 0.0001). Caesarean section as mode of delivery found significantly associated (p-value: 0.0033 ) with ICP. Insomnia (p-value: 0.0045); dyslipidemia (p-value: 0.0011); and postpartum haemorrhage (p-value: 0.0122) were also found significantly with ICP.

Conclusions: ICP can adversely affect fetal as well as maternal pregnancy outcomes. Maternal outcomes have good prognosis, but fetal outcomes can be improved by timely and effective intervention.
\end{abstract}

Keywords: Adverse perinatal outcomes, Fetal outcomes, Intrahepatic cholestasis of pregnancy, Maternal outcomes

\section{INTRODUCTION}

The liver is one of the many organs affected by the physiological and hormonal changes that occur during pregnancy. ${ }^{1}$ Hepatic disorders diagnosed before pregnancy may be unaffected or exacerbated by the pregnant state. $^{2}$ Liver disorders like intrahepatic cholestasis of pregnancy (ICP), toxaemias, HELLP syndrome may have a profound impact on the morbidity and mortality rates of the mother and fetus. ${ }^{3}$ Although an equivocal diagnosis is often difficult to make, it should be attempted in a timely manner so that optimal treatment can be determined. ${ }^{3}$ Intrahepatic cholestasis of pregnancy (ICP) is a cholestatic syndrome characterized by:

- Pruritus with onset in the second or third trimester of pregnancy.

- Elevated serum aminotransferases and bile acid levels.

- Spontaneous relief of signs and symptoms within two to three weeks after delivery. ${ }^{4}$ 
The syndrome of ICP, the most frequent of liver disorders specific to pregnancy, was recognized by Ahlfeld in 1883 as maternal pruritus and jaundice in the last trimester of pregnancy disappearing after delivery. ${ }^{5}$ The most comprehensive studies of modern era initially were performed in Scandinavian women in 1950s by Svanborg and Thorling. ${ }^{6-8}$

Reported incidence rates may vary with geographic location and race. ${ }^{8}$ Highest incidence rates of $12-20 \%$ are in Chile and rest include $9 \%$ in Bolivia, $2 \%-3 \%$ in Sweden $0.2 \%-0.8 \%$ in Australia, $0.2 \%$ in France, $0.13 \%$ in china and $0.1 \%$ in Canada. ${ }^{9-11}$ The incidence of ICP among Indian women has been reported to be around $1 \% .^{12,13}$ The exact cause of ICP is not known but genetic, hormonal and exogenous factors do play a role. ${ }^{14}$

Pruritus with or without jaundice, is a hall mark feature and involves palms, soles, extremities and trunk but spares mucous membranes. ${ }^{8,10,11}$ Pruritus persists with fluctuating severity till delivery and disappears after parturition. ${ }^{10,11}$

ICP is second only to viral hepatitis as a cause of jaundice during pregnancy and accounts for $20 \%$ of cases. ${ }^{15}$ Whenever jaundice occurs, it generally follows onset of pruritus by 2-4 weeks and usually resolves by 1 4 weeks post- partum. ${ }^{16}$ Typical features of obstructive jaundice, including pale stools and dark urine, accompany jaundice, but the patients feel generally well in contrast to viral hepatitis. ${ }^{17,18}$

ICP is associated with significant maternal morbidities. Women with ICP have an increased risk for postpartum haemorrhage, dyslipidaemia, preterm labour and operative interference. ${ }^{19,20}$ Fetus in ICP has been associated with an increased incidence of preterm labour, preterm prelabour rupture of membrane, fetal distress, abnormal CTG, meconium staining, spontaneous intrauterine death. ${ }^{19-22}$

The present study was done to evaluate the perinatal outcomes, maternal outcomes and fetal outcomes, of intrahepatic cholestasis in an Indian population.

\section{METHODS}

This was a prospective observational study, carried out to analyse the impact of intrahepatic cholestasis of pregnancy on the maternal and fetal outcome. The study was conducted in Department of Obstetrics and Gynaecology, Sri Maharaja Gulab Singh (SMGS) Hospital, Jammu and Gastroenterology section of Department of Medicine, Govt. Medical College, Jammu between July 2010 to June 2012.

The study was approved by Institutional Ethics Committee. Written informed consent was obtained from patient before enrolling them into the study.
Total 1100 pregnant women were screened during the study period. Patients with ICP were identified in maternity care units after eliciting history about itching. The diagnosis was based on:

- Clinical examinations, generalized pruritus in the absence of any dermatologic condition.

- Laboratory results, cholestatic pattern: serum aspartate and alanine transferase exceeding $40 \mathrm{U} / \mathrm{L}$; that returned to normal after delivery.

- No signs of viral hepatitis, negative results in assays for hepatitis B surface antigen and anti-hepatitis A and $\mathrm{C}$ antibodies.

- Normal ultrasonography of the liver and biliary tract.

To eliminate confounding factors for the present study, pregnancies with pregnancy induced hypertension and other liver diseases in pregnancy were excluded.

The pregnant women with ICP, underwent careful weekly outpatient clinical monitoring. During the visit, the patients were advised Nonstress Test (NST), amniotic fluid (AF) volume assessment using the four-quadrant amniotic fluid index (AFI) and liver function tests (LFT). Extreme elevation of LFT results combined with abnormal fetal heart rate (FHR) or decreased AFI necessitated hospitalization for induction of delivery process. Otherwise, labor was induced routinely at 38-40 weeks' gestation.

Patients' demographic data and pregnancy outcome measures were recorded in case record form. For the present study, following maternal outcomes were studied: insomnia due to severe pruritus; dyslipidemia; abnormal coagulation profile (increase PT); mode of delivery; preterm pre-labour rupture of membrane (PROM); and postpartum hemorrhage.

Abnormal cardiotocography (CTG); Birth weight (low birth weight $<2.5 \mathrm{~kg}$ ); small for gestational age (SGA: the bottom tenth percentile for weight according to week of gestation and gender); pre-term delivery (birth before 37 weeks of gestation); meconium stained liquor were assigned as fetal outcomes.

The data was entered in the excel sheet. The data was analyzed using descriptive statistics. The test variables were compared using Chi-square test for qualitative variables and Student's test for quantitative variables. The $\mathrm{p}$-value $<0.05$ was considered statistically significant for difference and association between variables.

\section{RESULTS}

Total 1100 pregnant women were screened during the study period. As per the diagnostic criteria defined criteria for intrahepatic cholestasis of pregnancy (ICP) for the present study, 62 pregnant women have been found to be suffering from ICP. This give the overall prevalence of $5.64 \%$ of HG for the present study (Figure 1). 


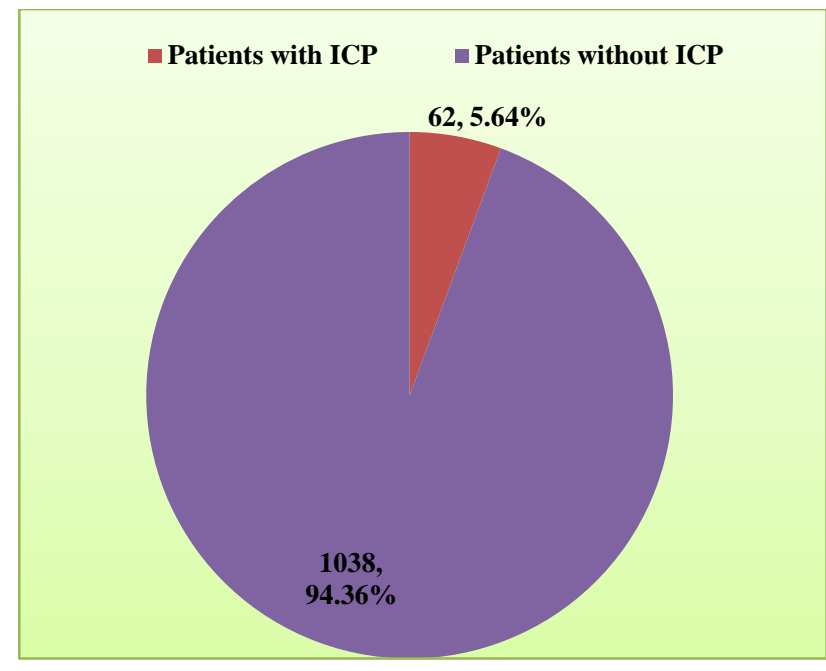

Figure 1: Prevalence of intrahepatic cholestasis of pregnancy (ICP).

According to Table 1, the most frequently affected (22, $35.48 \%$ ) age-group with ICP were belong to age > 35 years, followed by age groups of 30-34 years (18, $29.03 \%)$ and $25-29$ years $(13,20.97 \%)$. The age group of $>35$ years significantly (p-value: 0.0099) associated with development of intrahepatic cholestasis of pregnancy. Around two-third of the pregnant women with ICP were of more than 30 years. A majority of pregnant women with intrahepatic cholestasis of pregnancy was of multipara.

Table 1: Background characteristics of the study participants.

\begin{tabular}{|c|c|c|c|c|c|}
\hline \multirow[t]{2}{*}{ Parameters } & \multicolumn{2}{|c|}{$\begin{array}{l}\text { Patients with } \\
\text { ICP } \\
(\mathrm{N}=1038)\end{array}$} & \multicolumn{2}{|c|}{$\begin{array}{l}\text { Patients } \\
\text { with ICP } \\
(\mathrm{N}=62)\end{array}$} & \multirow[t]{2}{*}{ p-value } \\
\hline & $\mathbf{N}$ & $\%$ & $\mathbf{N}$ & $\%$ & \\
\hline \multicolumn{6}{|l|}{ Maternal age } \\
\hline$<20$ years & 12 & 1.16 & 1 & 1.61 & 0.7464 \\
\hline 20-24 years & 116 & 11.18 & 8 & 12.90 & 0.6760 \\
\hline $25-29$ years & 430 & 41.43 & 13 & 20.97 & $0.0454 *$ \\
\hline $30-34$ years & 378 & 36.42 & 18 & 29.03 & 0.2393 \\
\hline$>35$ years & 102 & 9.83 & 22 & 35.48 & $0.0099 * *$ \\
\hline \multicolumn{6}{|l|}{ Parity } \\
\hline Primipara & 524 & 50.48 & 18 & 29.03 & \multirow{2}{*}{$0.0428 *$} \\
\hline Multipara & 576 & 55.49 & 44 & 70.97 & \\
\hline \multicolumn{6}{|c|}{ Smoking habit } \\
\hline Non-smokers & 990 & 95.38 & 54 & 87.10 & \multirow{2}{*}{0.0832} \\
\hline Smokers & 48 & 4.62 & 8 & 12.90 & \\
\hline
\end{tabular}

ICP: Intrahepatic cholestasis of pregnancy; $*$ p-value $<0.05$ : significant difference; $* *$ p-value $<0.001$ : significant difference

The significant association (p-value: 0.0428 ) has been found between parity and intrahepatic cholestasis of pregnancy. There were no association found between smoking habit with development of intrahepatic cholestasis of pregnancy. Table 2 represent the fetal outcomes of pregnancy. Development of intrahepatic cholestasis of pregnancy was highly significantly associated with small for gestational age (SGA, p-value: 0.0003); abnormal cardiotocography (CTG, p-value: 0.0002 ); and meconium stained liquor (p-value: 0.0001). There were no association found between pre-term delivery and low birth weight with ICP.

Table 2: Fetal outcomes of pregnancy in study participants.

\begin{tabular}{|c|c|c|c|c|c|}
\hline \multirow[t]{2}{*}{$\begin{array}{l}\text { Fetal } \\
\text { outcomes }\end{array}$} & \multicolumn{2}{|c|}{$\begin{array}{l}\text { Patients } \\
\text { without } \\
\text { ICP } \\
(\mathrm{N}=1038)\end{array}$} & \multicolumn{2}{|c|}{$\begin{array}{l}\text { Patients } \\
\text { with ICP } \\
(\mathrm{N}=62)\end{array}$} & \multirow[t]{2}{*}{ p-value } \\
\hline & $\mathbf{N}$ & $\%$ & $\mathbf{N}$ & $\%$ & \\
\hline $\begin{array}{l}\text { Low birth } \\
\text { weight }\end{array}$ & 356 & 34.30 & 28 & 45.16 & 0.8128 \\
\hline SGA & 148 & 14.26 & 21 & 33.87 & $0.0003 *$ \\
\hline Pre-term & 302 & 29.09 & 25 & 40.32 & 0.0602 \\
\hline $\begin{array}{l}\text { Abnormal } \\
\text { CTG }\end{array}$ & 62 & 5.97 & 11 & 17.74 & $0.0002 *$ \\
\hline $\begin{array}{l}\text { Meconium } \\
\text { stained } \\
\text { liquor }\end{array}$ & 88 & 8.48 & 25 & 40.32 & $0.0001 *$ \\
\hline
\end{tabular}

ICP: Intrahepatic cholestasis of pregnancy; $*$ p-value $<0.001$ : significant difference

According to Table 3 regarding maternal outcomes of pregnancy, caesarean section as mode of delivery found significantly associated (p-value: 0.0033) with intrahepatic cholestasis of pregnancy. Insomnia (p-value: 0.0045); dyslipidemia (p-value: 0.0011); and postpartum haemorrhage (p-value: 0.0122) were also found significantly with ICP.

Table 3: Maternal outcomes of pregnancy in study participants.

\begin{tabular}{|c|c|c|c|c|c|}
\hline \multirow[t]{2}{*}{$\begin{array}{l}\text { Maternal } \\
\text { outcomes }\end{array}$} & \multicolumn{2}{|c|}{$\begin{array}{l}\text { Patients } \\
\text { without ICP } \\
(\mathrm{N}=1038)\end{array}$} & \multicolumn{2}{|c|}{$\begin{array}{l}\text { Patients } \\
\text { with ICP } \\
(\mathrm{N}=62)\end{array}$} & \multirow[t]{2}{*}{ p-value } \\
\hline & $\mathbf{N}$ & $\%$ & $\mathbf{N}$ & $\%$ & \\
\hline \multicolumn{6}{|l|}{ MOD } \\
\hline $\mathrm{CS}$ & 368 & 35.45 & 36 & 58.06 & \multirow{2}{*}{$0.0033 * *$} \\
\hline Vaginal & 670 & 64.55 & 26 & 41.94 & \\
\hline Insomnia & 248 & 23.89 & 38 & 61.29 & $0.0045 * *$ \\
\hline Dyslipidemia & 48 & 4.62 & 20 & 32.26 & $0.0011 * *$ \\
\hline $\mathrm{ACP}$ & 189 & 18.21 & 15 & 24.19 & 0.2388 \\
\hline PRM & 104 & 10.02 & 10 & 16.13 & 0.1252 \\
\hline PH & 98 & 9.44 & 12 & 19.35 & $0.0122 *$ \\
\hline
\end{tabular}

ICP: Intrahepatic cholestasis of pregnancy; * p-value < 0.05 : significant difference; $* *$ p-value $<0.001$ : significant difference, MOD: Mode of delivery; CS: Caesarean section; ACP: Abnormal coagulation profile; PRM: Pre-labour rupture of membrane; PH: Postpartum hemorrhage

Though, the incidences of abnormal coagulation profile and pre-labour rupture of membrane were more in the patients with, ICP, the present study failed to found out significant associations of abnormal coagulation profile 
and pre-labour rupture of membrane with intrahepatic cholestasis of pregnancy.

\section{DISCUSSION}

In the present study, total 1100 pregnant women were screened, and 62 pregnant women have been found to be suffering from ICP with prevalence of $5.64 \%$. The different study reported different incidence rates according to their geographic location and race. ${ }^{8}$ The reported incidence of ICP are -Chile: 12-20\%; Bolivia: 9\%; Sweden: $2 \%-3 \%$; $<1.0 \%$ in in Australia, France, China and Canada. ${ }^{9-11}$ The Indian studies reported the incidence of ICP among Indian women has been reported to be around $1 \%$, which is quite low in comparison to the present study. ${ }^{12,13}$ The present study was carried out at the tertiary care teaching hospital, so, chances of more complicated cases been treated in this set-up. This may be the reason for higher incidence of ICP in the present study. The present study has shown the age group of $>35$ years significantly (p-value: 0.0099) associated with development of intrahepatic cholestasis of pregnancy. Around two-third of the pregnant women with ICP were of more than 30 years. In a study done by Heinonen $\mathrm{S}$ et al., pregnant women with relatively advanced age $(>35$ years) were at increasing risk of developing ICP. ${ }^{23}$ The average maternal age of pregnant women with ICP has been found more than 30 years in an Australian study. ${ }^{24}$ There are many risk factors has been found for ICP which include advanced maternal age ( $\geq 35$ years); history of hepatitis $\mathrm{C}$; cholelithiasis; cholecystectomy; previous history of ICP; family history of ICP; and multiple gestation pregnancy. ${ }^{25-27}$

In the present study, a majority of pregnant women with intrahepatic cholestasis of pregnancy was of multipara. The significant association (p-value: 0.0428 ) has been found between parity and intrahepatic cholestasis of pregnancy. There was no significant difference in incidence according to parity (primigravida 9.7\% and multigravida $10.0 \%$ ) in a study done by Medda, et al. ${ }^{28}$ There were no association found between smoking habit with development of intrahepatic cholestasis of pregnancy. Development of intrahepatic cholestasis of pregnancy was highly significantly associated with small for gestational age (SGA, p-value: 0.0003); abnormal cardiotocography (CTG, p-value: 0.0002); and meconium stained liquor (p-value: 0.0001) in the present study. A similar study done by Medda, et al., including 100 patients with ICP, had shown following fetal outcomes: fetal distress (23\%); abnormal CTG (17.0\%), meconium stained liquor $(41.0 \%)$, preterm birth $(22.0 \%)$ excluding IUFD; low birth weight babies (32.0\%); neonates required admission to NICU $(27.0 \%){ }^{28}$

There are other studies in which lower mean birth weight has been noted, although this does not appear to be due to intrauterine growth restriction. ${ }^{23,29,30}$ Several studies have shown that there is no increase in the number of small for gestational age infants born to women with ICP. ${ }^{31,32}$
Abnormalities in CTG, both ante- and intrapartum, have been reported in association with ICP. ${ }^{30,33}$ In normal term pregnancies, the incidence of meconium staining of amniotic fluid (MSAF), a sign of fetal distress, is approximately $15 \%$. In case pregnancies complicated by ICP, the incidence of MSAF has been reported to increase up to $58 \% .^{30,34}$

The exact etio-pathogenesis for adverse fetal outcomes in pregnancies with ICP is not known. It may be related to an increased flux of bile acids into the fetal circulation, as indicated by elevated levels in amniotic fluid, cord serum and meconium. ${ }^{8}$ This hypothesis further supported by a recent study of fetal outcomes in ICP which has shown that the risk of adverse fetal outcomes increases with increasing levels of maternal serum bile acids. ${ }^{25}$

Caesarean section (CS) as mode of delivery found significantly associated (p-value: 0.0033) with intrahepatic cholestasis of pregnancy. Insomnia ( $\mathrm{p}$-value: 0.0045); dyslipidemia (p-value: 0.0011); and postpartum haemorrhage (PPH, p-value: 0.0122) were also found significantly with ICP in this study. In a study done by Medda et al., $62 \%$ of pregnancies were delivered by caesarean section [Elective CS $(32 \%)+$ Emergency CS (30\%)] which is comparable with rate $(58.06 \%)$ of CS in the present study. ${ }^{28}$ The same study has reported following maternal outcomes: insomnia (60\%); dyslipidemia (30\%); abnormal coagulation profile (19\%); PPH (10\%) and PROM (10\%). ${ }^{28}$ In term of prognosis, Maternal prognosis is good and and a majority of symptoms resolve rapidly after delivery, accompanied by normalization of LFT. ${ }^{4}$

\section{CONCLUSION}

Intrahepatic cholestasis of pregnancy is one of the common causes of hepatic impairment in pregnancy. ICP is associated with adverse fetal outcomes like, low birth weight babies; premature infants; abnormalities in CTG. ICP is also associated with maternal outcomes like, insomnia, dyslipidemia, PPH. Maternal outcomes have good prognosis but fetal outcomes can be improved by timely and effective intervention.

Funding: No funding sources Conflict of interest: None declared

Ethical approval: The study was approved by the Institutional Ethics Committee

\section{REFERENCES}

1. Soma-Pillay $\mathrm{P}$, Nelson-Piercy C, Tolppanen $\mathrm{H}$, Mebazaa A. Physiological changes in pregnancy. Cardiovasc J Afr. 2016;27(2):89-94.

2. Wolf JL. Liver disease in pregnancy. Med Clin North Am. 1996;80(5):1167-87.

3. Goel A, Jamwal KD, Ramachandran A, Balasubramanian KA, Eapen CE. Pregnancy-related 
liver disorders. J Clin Exp Hepatol. 2013;4(2):15162.

4. Pusl T, Beuers U. Intrahepatic cholestasis of pregnancy. Orphanet J Rare Dis. 2007;2(1):26.

5. Ghosh S, Chaudhuri S. Intra-hepatic Cholestasis of Pregnancy: A Comprehensive Review. Indian J Dermatol. 2013;58(4):327.

6. Svanborg A. A study of recurrent jaundice in pregnancy. Acta Obstet Gynecol Scand. 1954;33(4):434-44.

7. Thorling L. Jaundice in pregnancy; a clinical study. Acta Med Scand Suppl. 1955;302:1-123.

8. Geenes V, Williamson C. Intrahepatic cholestasis of pregnancy. World J Gastroenterol. 2009;15(17):2049-66.

9. Schorr-Lesnick B, Lebovics E, Dworkin B, Rosenthal WS. Liver diseases unique to pregnancy. Am J Gastroenterol. 1991;86(6):659-70.

10. Reyes H. The enigma of intrahepatic cholestasis of pregnancy: lessons from Chile. Hepatology. 1982;2(1):87-96.

11. Reyes H, Simon FR. Intrahepatic cholestasis of pregnancy: an estrogen-related disease. Semin Liver Dis. 1993;13(3):289-301.

12. Kenyon AP, Piercy CN, Girling J, Williamson C, Tribe RM, Shennan AH. Obstetric cholestasis, outcome with active management: a series of 70 cases. BJOG. 2002;109(3):282-8.

13. Ray A, Tata RJ, Balsara R. Cholestasis of pregnancy. J Obstet Gynecol India. 2005;55(3):247-50.

14. Nguyen KD, Sundaram V, Ayoub WS. Atypical causes of cholestasis. World J Gastroenterol. 2014;20(28):9418-26.

15. Floreani A. Hepatitis C and pregnancy. World J Gastroenterol. 2013;19(40):6714-20.

16. Riely CA, Bacq Y. Intrahepatic cholestasis of pregnancy. Clin Liver Dis. 2004,8(1):167-76.

17. Steven MM. Pregnancy and liver disease. Gut.1981;22(7):592-614.

18. Knox TA, Olans LB. Liver disease in pregnancy. N Engl J Med. 1996;335(8):569-76.

19. Saleh MM, Abdo KR. Consensus on the management of obstetric cholestasis: National UK survey. BJOG. 2007;114(1):99-103.

20. Mays JK. The active management of intrahepatic cholestasis of pregnancy. Curr Opinion Obstet Gynecol. 2010;22(2):100-3.

21. Nichols AA. Cholestasis of Pregnancy: A Review of the Evidence. J Perinat Neonatal Nurs. 2005;19(3):217-25.

22. Saleh MM, Abdo KR. Consensus on the management of obstetric cholestasis: National UK survey. BJOG. 2007;114(1):99-103.
23. Heinonen S, Kirkinen P. Pregnancy outcome with intrahepatic cholestasis. Obstet Gynecol. 1999;94(2):189-93.

24. Gardiner FW, McCuaig R, Arthur C, Carins T, Morton A, Laurie J, et al. The prevalence and pregnancy outcomes of intrahepatic cholestasis of pregnancy: A retrospective clinical audit review. Obstetric Medicine. 2018:1753495X18797749.

25. Guntupalli SR, Steingrub J. Hepatic disease and pregnancy: An overview of diagnosis and management. Crit Care Med 2005;33(10):S332-9.

26. Paternoster DM, Fabris F, Palu G, Santarossa C, Bracciante R, Snijders S. Intra-hepatic cholestasis of pregnancy in hepatitis $\mathrm{C}$ virus infection. Acta Obstet Gynecol Scand 2002;81(2):99-103.

27. Glantz A, Marschall HU, Mattsson LA. Intrahepatic cholestasis of pregnancy: Relationships between bile acid levels and fetal complication rates. Hepatology 2004;40(2):467-474.

28. Medda S, Sengupta S, Palo U. A study of the outcome of pregnancy complicated by obstetric cholestasis. Int J Reprod Contracept Obstet Gynecol. 2018;7(3):996-1001.

29. Johnston WG, Baskett TF. Obstetric cholestasis. A 14-year review. Am J Obstet Gynecol. 1979;133(3):299-301.

30. Reid R, Ivey KJ, Rencoret RH, Storey B. Fetal complications of obstetric cholestasis. Br Med J. 1976;1(6014):870-2.

31. Rioseco AJ, Ivankovic MB, Manzur A, Hamed F, Kato SR, Parer JT, et al. Intrahepatic cholestasis of pregnancy: a retrospective case-control study of perinatal outcome. Am J Obstet Gynecol. 1994;170(3):890-5.

32. Lunzer M, Barnes P, Byth K, O'Halloran M. Serum bile acid concentrations during pregnancy and their relationship to obstetric cholestasis. Gastroenterology. 1986;91(4):825-9.

33. Laatikainen T, Ikonen E. Fetal prognosis in obstetric hepatosis. Ann Chir Gynaecol Fenn. 1975;64(3):15564.

34. Shaw D, Frohlich J, Wittmann BA, Willms M. A prospective study of 18 patients with cholestasis of pregnancy. Am J Obstet Gynecol. 1982;142(6):6215 .

Cite this article as: Parihar S, Singh S. Perinatal outcomes and intrahepatic cholestasis of pregnancy: a prospective study. Int J Reprod Contracept Obstet Gynecol 2019;8:1177-81. 